\title{
Fatty acid oxidation and the $\beta$-oxidation complex in Mycobacterium leprae and two axenically cultivable mycobacteria that are pathogens
}

\author{
Paul R. Wheeler, ${ }^{*}$ Kathleen Bulmer and Colin Ratledge \\ Department of Applied Biology, University of Hull, Hull HU6 7RX, UK
}

(Received 15 May 1990; revised 29 October 1990; accepted 10 December 1990)

\begin{abstract}
Intact, non-growing Mycobacterium leprae, $M$. avium and $M$. microti oxidized a wide range of $1{ }^{-14} \mathrm{C}$-labelled fatty acids $\left(\mathrm{C}_{8}\right.$ to $\left.\mathrm{C}_{24}\right)$ to ${ }^{14} \mathrm{CO}_{2}$. Laurate $\left(\mathrm{C}_{12}\right)$ was oxidized most rapidly, and its oxidation by $M$. leprae was inhibited by the antileprosy agents Dapsone, clofazamine and rifampicin. Key enzymes of $\beta$-oxidation were detected in extracts from all three mycobacteria. All these activities (both in intact mycobacteria and the enzymes) were stimulated in $M$. avium grown in Dubos medium plus palmitate but activities in $M$. microti or $M$. avium grown either in Dubos medium with added liposomes or triolein, or in vivo were similar to those detected in the same strain grown in Dubos medium alone. $M$. avium could be grown in medium in which $95 \%$ of its fatty acyl elongase activity is acetyl-CoA dependent. In this medium growing $M$. avium organisms oxidized $\left[1-{ }^{14} \mathrm{C} \mid p\right.$ almitate to ${ }^{14} \mathrm{CO}_{2}$ but simultaneously elongated palmitate to $\mathrm{C}_{24}$ acids and even longer. Acetyl-CoA-dependent elongase activity is similar but clearly not identical to reversed $\beta$-oxidation, but the exact point(s) of difference have not yet been identified.
\end{abstract}

\section{Introduction}

The envelope of Mycobacterium leprae, the leprosy bacillus is highly lipid-rich and the bacteria consist of up to $40 \%$ lipid. Amongst the lipids are structural lipids such as the mycolic acids, 80-carbon fatty acyl ketoesters, which are covalently bound to the cell wall. There are also unbound lipids, including the well-documented 'phenolic glycolipid-I', which appears in a capsule-like layer and may be involved in protection of the leprosy bacillus and even in pathogenesis. Although lipids are clearly important quantitatively and individually, very little is known about lipid metabolism in M. leprae (for a recent review of metabolism, see Barclay \& Wheeler, 1989). Recent work has shown that palmitate is incorporated by intact $M$. leprae (Wheeler \& Ratledge, 1988) and that the carbon from palmitate appears in 'phenolic glycolipid-I' - a lipid found only in $M$. leprae on thin-layer chromatography (Franzblau et al., 1987). Furthermore, palmitate is rapidly catabolized to $\mathrm{CO}_{2}$ (Franzblau, 1988; Wheeler \& Ratledge, 1988) and

\footnotetext{
Abbreviations: $8: 0$, octanoate; $10: 0$, decanoate; $12: 0$, dodecanoate (laurate); 14:0, tetradecanoate (myristate); 16:0, hexadecanoate (palmitate); 18:0, octadecanoate (stearate); $18: 1$ or $18: 1$ (c9), cisoctadec-9-enoate (oleate); 20:4, arachidonate; 24:0, lignocerate; DDS, 4,4-diaminodiphenyl sulphone (Dapsone); B663, clofazimine; DCPIP, dichlorophenol-indophenol, PMS, phenazine methosulphate.
}

stimulates oxygen uptake by suspensions of purified $M$. leprae (Ishaque, 1989).

The purpose of this study was to compare the utilization of a range of exogenous fatty acids through the $\beta$-oxidation pathway for fatty acid oxidation. In showing which fatty acids are most readily oxidized by $M$. leprae, this study may point to activities which may prove most useful to measure in devising radiometric tests for viability and drug susceptibility of $M$. leprae. Already, it is known that palmitate oxidation is inhibited by a wide range of antileprosy agents (Franzblau, 1988). The measurement of ${ }^{14} \mathrm{CO}_{2}$ release from ${ }^{14} \mathrm{C}$-labelled fatty acids by $M$. leprae (Franzblau, 1988; Wheeler \& Ratledge, 1988) reflects activity in non-dividing bacteria and is thus distinct from the BACTEC method in which ${ }^{14} \mathrm{C}$-labelled fatty acid, included in the growth medium, allows rapid detection, by monitoring ${ }^{14} \mathrm{CO}_{2}$ release, of the actual multiplication of slow-growing organisms such as $M$. tuberculosis (see, for example, Camargo \& Wagner, 1987; Heifets et al., 1985).

Interest is added to the present study because the major activity for anabolism of fatty acids, which in $M$. leprae, M. avium (Wheeler et al., 1990) and $M$. lepraemurium (Kusaka, 1977) is by fatty acid elongation, involves direct incorporation of acetyl-CoA into growing fatty acyl chains. In these mycobacteria, malonyl-CoAdependent elongase activity, which is energetically a 


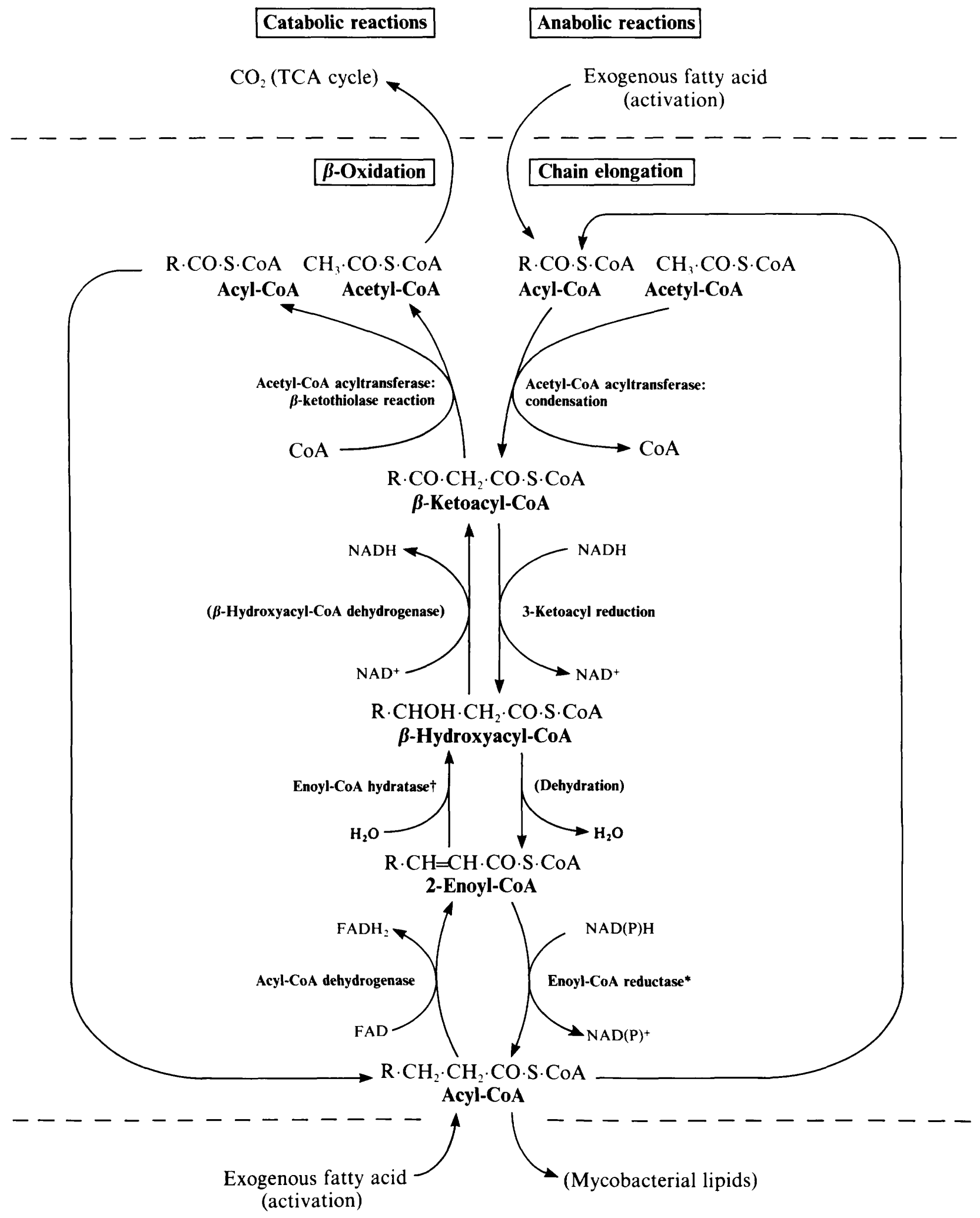

Fig. 1. Scheme showing how the reactions studied in this work are involved in $\beta$-oxidation and acetyl-CoA-dependent fatty acyl chain elongation. The overall reactions are described in the boxes; $\beta$-oxidation/chain elongation per se is delineated by dashed lines. All the individual activities, except the essentially reversible reactions in parentheses, were studied in the work described in this paper. ${ }^{*} A$ trace of acyl-CoA : NAD(P) oxidoreductase was detected; †assayed with trans-2-enoyl-CoAs only. 
more favourable reaction is barely, if at all, detectable. This means either that $\beta$-oxidation enzymes (which release acetyl-CoA from fatty acyl-CoA esters) participate in these synthetic reactions by a reversal of activity (Nishimaki-Mogami et al., 1987; Shimikata et al., 1980) or that analogous but different enzymes must fulfil the means of elongating fatty acids by acetyl-CoA attachment (Fig. 1). Therefore, key enzyme activities for the reactions shown in Fig. 1 were sought for both catabolic and anabolic metabolism of fatty acids.

Finally, intracellular mycobacteria inhabit a lipid-rich environment: the cells in which they reside are usually macrophages (Lowrie, 1983) or, for M. leprae, Schwann cells (Mukherjee \& Antia, 1985). Therefore, the availability of host cell lipids for fatty acid oxidation in intact mycobacteria and their effects on activities of enzymes in the $\beta$-oxidation complex was also investigated in strains of $M$. microti and $M$. avium which are highly pathogenic for mice. These strains were grown in experimental animals as well as axenically with and without supplied lipids. In this way, results obtained with $M$. leprae, which can only be grown in vivo, can be interpreted in a more valid manner than by simply investigating fatty acid metabolism in $M$. leprae alone.

\section{Methods}

Mycobacteria from experimentally infected animals. M. leprae, $M$. avium CR1/69, and $M$. microti OV254 were obtained from heavily infected tissue as described previously (Wheeler, 1987). Briefly, bacteria were separated from tissue by a method (World Health Organization, 1980) involving differential then density-gradient centrifugation. For suspensions used to provide cell-free extracts for enzyme work, further purification was achieved on an aqueous two-phase system. Some suspensions were treated for 30 min with $0.5 \mathrm{M}-\mathrm{NaOH}$ at $25^{\circ} \mathrm{C}$ (Wheeler et al., 1982) to abolish host-derived activities adsorbed to the surface of the bacteria. Host-derived organisms were enumerated by direct counting. Compared with determination of dry weight, $10^{10}$ $M$. leprae $\cong 1 \mathrm{mg}$ dry wt organisms.

Mycobacteria grown in cell-free media. Bacteria (the inoculum was $1 \mathrm{ml}$ from a flask including the corresponding medium at the stage when harvesting was done; Wheeler, 1987) were grown in $100 \mathrm{ml}$ Dubos medium (Chadwick, 1982) in $250 \mathrm{ml}$ flasks, shaken at 200 r.p.m. at $37^{\circ} \mathrm{C}$, then harvested as described previously (Wheeler, 1987). $M$ microti OV254 was harvested after $15 \mathrm{~d}$ and $M$. avium CR1/69 after $20 \mathrm{~d}$. Additions to the Dubos medium (see Table 2) were as follows. For liposomes, phosphatidylcholine, cholesterol and $s n$-1,2-dipalmitoylphosphatidic acid in the molar ratio $10: 10: 1$, prepared as described previously (Kondo et al., 1985; Wheeler et al., 1990) and totalling $150 \mu \mathrm{g}$ lipid per $\mathrm{ml}$ of medium. Other additions were sodium palmitate, trioleoylglycerol (triolein) or methyllaurate (Lancaster synthesis, Morecambe, Lancs, UK), all at $100 \mu \mathrm{g}$ lipid per $\mathrm{ml}$ of medium. These suspensions were prepared by first dispersing the lipid in water at $10 \mathrm{mg} \mathrm{ml}^{-1}$ by sonication for about $10 \mathrm{~s}$ using a Dawe Soniprobe at low energy. Batches of $M$. avium were also grown in Sauton's medium (Chadwick, 1982) solely for determination of $\beta$ ketothiolase. Mycobacteria were enumerated by determination of their dry weight. Compared with direct counting, $1 \mathrm{mg}$ dry wt $M$. microti $\cong 10^{10}$ organisms and $1 \mathrm{mg}$ dry wt $M$. avium $\cong 2 \times 10^{10}$ organisms.

Preparation of cell-free extracts of mycobacteria. Mycobacteria were ultrasonically disrupted and clarified as described previously (Wheeler et al., 1990) to give extracts in $0.2 \mathrm{M}$-potassium phosphate, $\mathrm{pH} 7$, with $5 \mathrm{mM}$-dithiothreitol, or $5 \mathrm{mM}-\mathrm{MES} / \mathrm{KOH}, \mathrm{pH} 7$, with $1 \mathrm{mM}-\mathrm{MgCl}_{2}$. Some extracts were dialysed using ultrafiltration cones with a cut-off of $M_{\mathrm{r}} 25000$ as described previously (Wheeler, 1984). There was no marked difference in the specific activities of the enzymes studied in this paper between the extracts prepared in the different ways described above.

Incubations of mycobacteria with radioisotopically labelled substrates. Mycobacteria, as washed suspensions, were incubated in a buffer including $0.05 \%$ Tween 80 which did not support growth, and $1^{-14} \mathrm{C}$. labelled fatty acid, as described for palmitic acid by Wheeler \& Ratledge (1988) except that $5 \mathrm{nmol}$ fatty acid was included in each $200 \mu \mathrm{l}$ incubation mixture. In order to achieve this, the following amounts of $1{ }^{14} \mathrm{C}$-labelled fatty acid were added to each tube as solutions in toluene or toluene/ethanol (as supplied) and dried aseptically: octanoate, myristate, palmitate (all $2 \mathrm{TBq} \mathrm{mol}^{-1}$ ), $10000 \mathrm{~Bq}$; decanoate $(1.92 \mathrm{~Bq}) 9620 \mathrm{~Bq}$; laurate $\left(2.15 \mathrm{TBq} \mathrm{mol}^{-1}\right)$, $10730 \mathrm{~Bq}$; stearate, oleate (both at $2.07 \mathrm{TBq} \mathrm{mol}^{-1}$ ), $10360 \mathrm{~Bq}$; lignocerate $\left(1.0 \mathrm{TBq} \mathrm{mol}^{-1}\right), 8510 \mathrm{TBq} \mathrm{mol}^{-1}$; arachidonate $(2 \cdot 15 \mathrm{TBq}$ $\mathrm{mol}^{-1}$ ), $5500 \mathrm{~Bq}$ plus $2.4 \mathrm{nmol}$ unlabelled arachidonic acid (Sigma). All radiochemicals were from Amersham except lignocerate which was from CEA, France. At the end of the incubation period at $34^{\circ} \mathrm{C}-1 \mathrm{~h}$ for M. microti and M. avium, $20 \mathrm{~h}$ for M. leprae - bacteria were collected on GFC filters (Whatman) and washed four times with buffered Tween 80. The ${ }^{14} \mathrm{CO}_{2}$ evolved during incubation was trapped in $400 \mu 11 \mathrm{M}$ $\mathrm{NaOH}$. Assimilation was determined by measuring the radioactivity on the washed filters. Evolution of ${ }^{14} \mathrm{CO}_{2}$ was determined by measuring the radioactivity, as $\mathrm{Na}_{2}{ }^{14} \mathrm{CO}_{3}$, trapped in the $\mathrm{NaOH}$. Incubations which were contaminated (checked by plating $5 \mu$ samples on to nutrient agar) were discarded. Controls contained heat-killed $\left(100^{\circ} \mathrm{C}, 15 \mathrm{~min}\right)$ bacteria, and values for radioactivity assimilated and for radioactivity evolved as ${ }^{14} \mathrm{CO}_{2}$ obtained in controls were subtracted from values for radioactivity in corresponding incubations with live bacteria before the results presented in the text and Tables 1 to 3 were calculated. Full details of all the components of incubation mixtures are presented in previous papers (Wheeler, 1984; Wheeler \& Ratledge, 1988) and non-specific adsorption of fatty acids to intact mycobacteria as suggested by high values of radioactivity in controls was discussed previously (Wheeler \& Ratledge, 1988). Some incubations included the antileprosy agents DDS (Dapsone) (Sigma), clofazimine (B663) (a gift from Dr S. O'Sullivan, Medical Research Council of Ireland, Dublin) or rifampicin (Sigma).

Additionally, an experiment was done (in duplicate) involving incubating growing $M$. avium with $\left[1^{-14} \mathrm{C}\right]$ palmitic acid. A 14 -d-old culture, growing arithmetically (Wheeler, 1987) in Dubos medium with $100 \mu \mathrm{g}$ sodium palmitate $\mathrm{ml}^{-1}$, was used. A $25 \mathrm{ml}$ sample of the culture was poured aseptically into a sterile $100 \mathrm{ml}$ flask containing $74 \mathrm{MBq}$ solid $\left[1^{-14} \mathrm{C}\right]$ palmitic acid. The flask was swirled for $1 \mathrm{~min}$ to disperse the $\left[{ }^{14} \mathrm{C}\right]$ palmitic acid, placed in a sealed container which also included a vial with $1 \mathrm{ml} 0.5 \mathrm{M}-\mathrm{NaOH}$, and shaken at $37^{\circ} \mathrm{C}$ for $4 \mathrm{~h}$; the trapped ${ }^{14} \mathrm{CO}_{2}$ was collected and determined as described above. Bacteria were collected on GFC filters (i) to determine assimilation and (ii) to extract unbound lipids. For the latter the bacteria, collected on the filters, were washed four times with buffered Tween 80 , then each filter (with the bacteria) was refluxed for $1 \mathrm{~h}$ in $4 \mathrm{ml}$ chloroform/methanol $(2: 1, \mathrm{v} / \mathrm{v})$. Each filter was then removed, the solvent washed once with $2 \mathrm{ml}$ distilled water, dried, and the fatty acyl moieties in the extracted lipids methylated under acid conditions (Minnikin et al., 1980). Fatty acid methyl esters were separated from other lipids by TLC (Minnikin et al., 1980) and analysed for their degree of saturation, and by gas 
chromatography followed by collection of fatty acid esters and determination of their radioactivity. For the former, HPTLC plates (Merck; HPTLC silica gel 60 with concentrating zone) were dipped into a saturated solution of $\mathrm{AgNO}_{3}$ in acetone, dried with a flow of cool air, and used immediately; a sample of fatty acid methyl esters was applied, with standards (16:0,18:1, 18:2 and 18:3 methyl esters), dried, and plates were developed once in dichloromethane. The position of lipids was detected by spraying with 2,7-dichlorofluorescein. Relative positions of lipids were the same as when separated by argentation $\left(\mathrm{AgNO}_{3}\right)$-TLC using standard TLC plates, with 16:0 methyl ester running nearest to the solvent first and $18: 2$ and 18:3 esters remaining near the origin and not always separating well. Radioactivity in the resolved lipids was detected by scraping and counting (Wheeler \& Ratledge, 1988). Separation of labelled fatty acid esters by gas chromatography was done using a Pye Unicam chromatograph, injecting samples (up to $5 \mu \mathrm{l}$ in chloroform) of fatty acid methyl esters into a column $(2 \mathrm{~m} \times 4 \mathrm{~mm})$ of $10 \%$ diethylene glycol succinate (PhaseSep, Queensferry, Clwyd, UK). The column was maintained at $195^{\circ} \mathrm{C}$ with $\mathrm{N}_{2}$ as the carrier gas. Lipids were detected by flame ionization and collected in capillaries kept at $-20^{\circ} \mathrm{C}$, the sample being split so that 1 part went through the detector to 19 parts into the capillary. Material was eluted with chloroform from each capillary into a scintillation vial, dried, and radioactivity determined by scintillation counting in Bray's fluid $(4 \mathrm{~g}$ 2,5-diphenyloxazole, $60 \mathrm{~g}$ naphthalene, $100 \mathrm{ml}$ methanol and $20 \mathrm{ml}$ ethanediol, made up to 1 litre with dioxan). Duplicate samples of mycobacterial lipids were run, one with standards (methyl esters of saturated fatty acids of 16, 18, 19, 20, 21,22 and 24 carbon atoms), and one without standards.

Enzyme assays. All were done at $25^{\circ} \mathrm{C}$; the reaction volume was $500 \mu$ l. Optimal assay conditions were established in previous work done with M. smegmatis (Kikuchi \& Kusaka, 1984; Shimikata et al., 1980).

Acyl-CoA dehydrogenase [EC 1.3.99.3; acyl-CoA :(acceptor) oxidoreductase - see Fig. 2] was assayed by incubating extracts with $50 \mathrm{~mm}$-potassium phosphate (pH 7.6), $0 \cdot 3 \mathrm{~mm}-\mathrm{Na}_{2}$ EDTA, $30 \mu \mathrm{M}-2,6-$ dichlorophenol-indophenol (DCPIP), $1.4 \mathrm{~mm}$-phenazine methosulphate (PMS) and either $30 \mu \mathrm{M}$-decanoyl-CoA or palmitoyl-CoA. $\Delta A_{600}$ was followed against a control containing no acyl-CoA. In order to determine whether $\mathrm{NAD}^{+}$- or $\mathrm{NADP}^{+}$oxidoreductase (EC 1.3.1.8 see Fig. 1) was present two procedures, with variants, were used: (i) EDTA and PMS were replaced either by $1 \mathrm{mM}^{-N A D P}{ }^{+}$and $\Delta A_{340}$ was followed, or by $\mathrm{NAD}^{+}$together with diaphorase $(0.1$ unit, porcine; Sigma) and $600 \mu \mathrm{M}-p$-iodonitrotetrazolium and $\Delta A_{500}$ followed; alternatively, (ii) $1 \mathrm{~mm}-\mathrm{NAD}^{+}$and diaphorase (0.1 unit) or $1 \mathrm{~mm}-\mathrm{NADP}^{+}$ and ferridoxin: $\mathrm{NADP}^{+}$reductase (from spinach, with NADPH diaphorase activity; Sigma) replaced PMS, and controls were done without $\mathrm{NAD}^{+}$or diaphorase, and $\Delta A_{600}$ (for DCPIP) was followed.

Enoyl-CoA reductase [EC 1.3.1.8; acyl-CoA : NAD(P) ${ }^{+}$oxidoreductase - see Fig. 2] activity was assayed by incubating extracts with $0.1 \mathrm{M}$-potassium phosphate (pH 5.5), $100 \mu \mathrm{M}-\mathrm{NADH}$, and either $100 \mu \mathrm{M}$-crotonoyl-CoA or $100 \mu \mathrm{M}$-trans-dec-2-enoyl-CoA. $\Delta A_{340}$ was followed against a control containing no enoyl-CoA. trans-Dec-2-enoic acid, purchased from Lancaster Synthesis, and CoA (lithium salt), from Sigma, were used for preparation of trans-dec-2-enoyl-CoA by the mixed anhydride method (Schulz, 1974).

Enoyl-CoA hydratase (EC 4.2.1.17; L-3-hydroxyacyl-CoA hydrolyase) was assayed in crude extracts of the mycobacteria by a coupled assay system. Extracts were incubated with 50 mM-potassium phosphate (pH 7.0), $200 \mu \mathrm{M}-\mathrm{NAD}^{+}, 600 \mu \mathrm{M}-p$-iodonitrotetrazolium violet, $\beta$-hydroxyacyl CoA dehydrogenase (1 unit, porcine heart; Sigma), diaphorase (0.1 unit, porcine; Sigma) and either $100 \mu \mathrm{M}$-crotonyl-CoA or $100 \mu \mathrm{M}$-trans-dec-2-enoyl-CoA; $\Delta A_{500}$ was followed against a control containing no enoyl-CoA.

$\beta$-Hydroxyacyl-CoA dehydrogenase (EC 1.1.1.35; L-3-hydroxy-
acyl-CoA : $\mathrm{NAD}^{+}$oxidoreductase) was assayed by incubating extracts with $100 \mathrm{~mm}$-potassium phosphate $(\mathrm{pH} 7.0), 0.2 \mathrm{mg}$ bovine serum albumin (Sigma) $\mathrm{ml}^{-1}, 0.1 \mathrm{mM}-\mathrm{NADH}$ and $30 \mu \mathrm{M}$-acetoacetyl-CoA; $\Delta A_{340}$ was followed against a control containing no acetoacetyl-CoA.

Acetyl-CoA acyltransferase ( $\beta$-ketothiolase) (EC 2.3.1.16; acylCoA : acetyl-CoA $C$-acyltransferase) was assayed in extracts made by sonicating bacteria as described previously (Wheeler et al., 1990) but in $0.5 \mathrm{M}$-Tris $/ \mathrm{HCl}, \mathrm{pH} 8$ containing $25 \mathrm{~mm}-\mathrm{MgCl}_{2}, 5 \%$ (w/v) glycerol and $2 \mathrm{mM}$-2-mercaptoethanol. Extract $(400 \mu \mathrm{l})$, or extract diluted with the above sonication mixture to $400 \mu \mathrm{l}$ was mixed with substrates (final concentrations in the $500 \mu \mathrm{l}$ mixtures shown) to give reaction volumes of $500 \mu \mathrm{l}$, as follows. For the biosynthetic direction, $30 \mu \mathrm{M}$-acetyl-CoA and either decanoyl-CoA or palmitoyl-CoA at either $25 \mu \mathrm{M}$ or $75 \mu \mathrm{M}$ were included, together with, as a coupled enzyme, $\beta$-hydroxyacyl-CoA dehydrogenase ( 1 unit, porcine heart; Sigma) and $100 \mu \mathrm{M}-\mathrm{NADH}$. $\Delta A_{340}$ was followed against a control containing acetyl-CoA but no decanoyl-CoA or palmitoyl-CoA. Subsequently, it was found that omitting $\beta$-hydroxyacyl-CoA dehydrogenase did not affect the reaction rate, presumably because the activity of mycobacterial $\beta$-hydroxyacyl$\mathrm{CoA}$ dehydrogenase was sufficient for the coupled reaction to take place. For the catabolic direction, $30 \mu \mathrm{M}$-acetoacetyl-CoA was included and $\triangle A_{303}$ was followed against a control containing no acetoacetylCoA (Binstock \& Schulz, 1981). For acetoacetyl-CoA, $\varepsilon_{1 \mathrm{~cm}}^{1 \mathrm{~mm}}=16.9$.

\section{Results}

\section{Oxidation of fatty acids by intact, non-growing mycobacteria}

Suspensions of intact $M$. leprae, $M$. microti and $M$. avium all oxidized a similar range of fatty acids through to $\mathrm{CO}_{2}$ The complete range of fatty acids tested is shown for $M$. leprae (Table 1). For both $M$. microti and $M$. avium, the pattern of fatty acid oxidation was similar, i.e. lauric acid was oxidized most rapidly (rates shown in Table 2), followed by octanoate, myristate and decanoate at similar rates, while the long-chain lignocerate was oxidized relatively slowly. The rate of oxidation was not related to the rate of assimilation (the appearance of label in intact, living organisms, with background label in killed organisms subtracted) in $M$. leprae (Table 1), or in $M$. microti or $M$. avium, where ${ }^{14} \mathrm{C}$ was assimilated most rapidly in incubations with myristate or palmitate (usually over $50 \%$ of the label supplied per $10^{10}$ organisms in $1 \mathrm{~h}$ ) followed by arachidonate.

The results in Tables 1 and 2 were obtained in incubations at $\mathrm{pH} 7 \cdot 0$. When additional, duplicate incubations with both laurate and palmitate at changed $\mathrm{pH}$ were done with an isolate of $M$. leprae, activity was similar to that shown in Table 1 at pH 5.5 (buffer $50 \mathrm{~mm}$ $\mathrm{MES} / \mathrm{KOH}$ ) but about half the values shown in Table 1 when $50 \mathrm{~mm}$-HEPES/KOH at $\mathrm{pH} 8.0$ was used.

Growth of mycobacteria in media containing lipids did not have any clearly discernible effect on the rate at which they subsequently oxidized fatty acids, except that the oxidative activity was possibly higher in $M$. avium 
Table 1. Incorporation and oxidation of $1-^{14} \mathrm{C}$-labelled fatty acids by suspensions of $M$. leprae

Intact $M$. leprae organisms $\left(2\right.$ to $\left.10 \times 10^{9}\right)$ were incubated with $5 \mathrm{nmol} 1^{14} \mathrm{C}$-labelled fatty acid in $200 \mu$ l. Three isolates of $M$. leprae organisms, as suspensions, were prepared : two isolates from one armadillo and a third isolate from another armadillo. Each determination of assimilation and ${ }^{14} \mathrm{CO}_{2}$ evolved was done in duplicate for each isolate. From one infected armadillo, suspensions of $\mathrm{NaOH}$-treated $M$. leprae and, on a separate occasion, untreated $M$. leprae organisms were obtained. There were no marked differences between their activities so results from the $\mathrm{NaOH}$-treated as well as untreated $M$. leprae were used to calculate the mean values below. The values are the percentage of radioactivity supplied that was assimilated or evolved as ${ }^{14} \mathrm{CO}_{2}$ per $10^{10}$ organisms in $20 \mathrm{~h}, \pm$ SEM.

\begin{tabular}{|c|c|c|}
\hline \multirow{2}{*}{$\begin{array}{l}\text { Fatty } \\
\text { acid }\end{array}$} & \multicolumn{2}{|c|}{$\begin{array}{l}\text { Percentage of radioactivity } \\
\text { supplied that was: }\end{array}$} \\
\hline & Assimilated & Evolved as ${ }^{14} \mathrm{CO}_{2}$ \\
\hline Octanoate & $9 \cdot 3 \pm 4 \cdot 5$ & $6 \cdot 2 \pm 1 \cdot 5$ \\
\hline Decanoate & $10 \cdot 4 \pm 2 \cdot 1$ & $4.5 \pm 1 \cdot 2$ \\
\hline Laurate & $7 \cdot 4 \pm 2 \cdot 3$ & $11.9 \pm 1.2$ \\
\hline Myristate & $10 \cdot 4 \pm 2 \cdot 1$ & $4.0 \pm 0.5$ \\
\hline Palmitate & $8 \cdot 3+1 \cdot 1$ & $3.4+1.0$ \\
\hline Stearate & $9.9 \pm 1.6$ & $0.5 \pm 0.1$ \\
\hline Lignocerate & $7 \cdot 8 \pm 9 \cdot 3^{*}$ & $0.10 \pm 0.03$ \\
\hline Oleate & $6 \cdot 2 \pm 1 \cdot 7$ & $0.25 \pm 0.11$ \\
\hline Arachidonate & $10.0 \pm 3.3$ & $0.7 \pm 0.3$ \\
\hline
\end{tabular}

* For each separate isolate, radioactivity in live bacteria was always higher than in controls: the considerable variation was between isolates. Also, radioactivity associated with live bacteria was only 1.2 to 2 times the radioactivity associated with heat-killed controls.
Table 2. Oxidation of laurate and palmitate by individual isolates of $M$. microti and $M$. avium

Intact mycobacteria $\left(4\right.$ to $\left.12 \times 10^{9}\right)$ were incubated at $34^{\circ} \mathrm{C}$ with all the $1{ }^{14} \mathrm{C}$-labelled fatty acids shown in Table 1 ; only results with laurate and palmitate are shown here (see text for results of other incubations). Individual isolates or batches of bacteria are identified below by the medium from which the bacteria were harvested. For each isolate, determinations of ${ }^{14} \mathrm{CO}_{2}$ evolved from each $1-{ }^{14} \mathrm{C}$-labelled fatty acid were done in duplicate, and were always within $15 \%$ of the mean values shown below. Values are the percentage of radioactivity supplied evolved as ${ }^{14} \mathrm{CO}_{2}$ per $10^{10}$ organisms in $1 \mathrm{~h}$.

\begin{tabular}{|c|c|c|c|c|}
\hline \multirow[b]{3}{*}{ Isolate/batch } & \multicolumn{4}{|c|}{$\begin{array}{l}\text { Percentage of radioactivity } \\
\text { evolved as }{ }^{14} \mathrm{CO}_{2}\end{array}$} \\
\hline & \multicolumn{2}{|c|}{ M. microti plus: } & \multicolumn{2}{|c|}{ M. avium plus: } \\
\hline & Laurate & Palmitate & Laurate & Palmitate \\
\hline Dubos (1) & $10 \cdot 7$ & $1 \cdot 1$ & $9 \cdot 3$ & 0.5 \\
\hline Dubos (2) & $5 \cdot 6$ & $0 \cdot 7$ & $10 \cdot 7$ & $0 \cdot 7$ \\
\hline Dubos + liposomes* (1) & 1.5 & $0 \cdot 2$ & $6 \cdot 5$ & $2 \cdot 2$ \\
\hline Dubos + liposomes* (2) & $9 \cdot 3$ & $1 \cdot 0$ & 1.9 & $0 \cdot 2$ \\
\hline Dubos + palmitate & ND & ND & $23 \cdot 1$ & 1.8 \\
\hline Dubos + methyl laurate* & ND & ND & $17 \cdot 6$ & $2 \cdot 7$ \\
\hline Dubos + triolein $*$ & ND & ND & 8.0 & 0.5 \\
\hline Mice (1) & $5 \cdot 0$ & $0 \cdot 6$ & $1 \cdot 5$ & $0 \cdot 1$ \\
\hline Mice (2) & ND & ND & $5 \cdot 0$ & $1 \cdot 0$ \\
\hline
\end{tabular}

ND, Not done, usually because of severe inhibition of axenic growth of $M$. microti by palmitate or triolein.

- Total lipid content 100 to $150 \mu \mathrm{g} \mathrm{ml}^{-1}$ : for details of how supplied, and content of liposomes, see Methods.

Table 3. Effect of antileprosy agents on laurate oxidation by M. leprae ester (Table 2). More striking, however, was the great variation between isolates from tissues or between individual batches of bacteria grown axenically in the same medium (Table 2), even though bacteria were always harvested during a phase of slow, arithmetic growth before the stationary phase (see Wheeler, 1987, for growth curves).

Despite the variation between isolates, oxidation of fatty acid by replicate incubations of mycobacteria from the same isolate was consistent (see legend to Table 2). This finding was exploited in previous work to test the effects of inhibitors and antileprosy agents on oxidation of $\left[1{ }^{-14} \mathrm{C}\right]$ palmitate to ${ }^{14} \mathrm{CO}_{2}$ (Franzblau, 1988). In the present work, oxidation of $\left[1{ }^{-14} \mathrm{C}\right]$ laurate by $M$. leprae was shown to be inhibited by DDS and B663 at all concentrations used and rifampicin at $3 \mu \mathrm{g} \mathrm{m}^{-1}$ and above (Table 3). The solvents used to dissolve the agents (dimethylsulphoxide at up to $0.1 \%$ in incubations for B663 and rifampicin; $\mathrm{HCl}$ at up to $0.1 \mathrm{~mm}$ for DDS) did not effect oxidation of lauric acid.

\begin{abstract}
Intact $M$. leprae was incubated with $\left[1-{ }^{14} \mathrm{C}\right]$ lauric acid as described in Table 1. The mean rate of ${ }^{14} \mathrm{CO}_{2}$ evolution in six control incubations including live $M$. leprae was $934 \mathrm{~Bq}$ per $10^{10} \mathrm{M}$. leprae in $20 \mathrm{~h}$. This rate is assigned a relative activity of $100-$ of the six incubations, the lowest individual incubation had a relative activity of 72 . Incubations with antileprosy agents were done at the same time as the controls, using the same isolate. For each agent at each concentration, incubations were done in triplicate.
\end{abstract}

\begin{tabular}{lccc}
\hline \hline $\begin{array}{c}\text { Antileprosy } \\
\text { agent }\end{array}$ & Concn & $\begin{array}{c}\text { Relative } \\
\text { activity }\end{array}$ & $P^{*}$ \\
\hline DDS & $10 \mathrm{ng} \mathrm{ml}^{-1}$ & 38 & $<0.05$ \\
& $30 \mathrm{ng} \mathrm{ml}^{-1}$ & 30 & $<0.05$ \\
& $100 \mathrm{ng} \mathrm{ml}^{-1}$ & 24 & $<0.05$ \\
B663 & $200 \mathrm{ng} \mathrm{ml}^{-1}$ & 36 & $<0.05$ \\
& $20 \mu \mathrm{g} \mathrm{ml}^{-1}$ & 27 & $<0.05$ \\
Rifampicin & $1 \mu \mathrm{g} \mathrm{ml}^{-1}$ & 70 & $>0 \cdot 10$ \\
& $3 \mu \mathrm{g} \mathrm{ml}^{-1}$ & 26 & $<0 \cdot 05$ \\
& $10 \mu \mathrm{g} \mathrm{ml}^{-1}$ & 15 & $<0.05$ \\
\hline \hline
\end{tabular}

* Determined using the Wilcoxon rank-sum test (see Colquhoun, 1971); significant inhibition at $P<0.05$. 
Enzyme activities involved in $\beta$-oxidation and acetyl-CoAdependent chain elongation

Except for acetyl-CoA acyltransferase, all activities of the $\beta$-oxidation pathway assayed were detected in extracts of mycobacteria, including mycobacteria harvested from tissues of experimentally infected animals (Table 4). It was shown that acetyl-CoA acyltransferase was present in the mycobacteria only by growing them to as high a yield as possible: $M$. avium in Sauton's medium, $M$. microti in Dubos medium and $M$. leprae (a single isolate) harvested from armadillo spleen. Not only were the specific activities of this enzyme low, it was also unstable, with 20 to $40 \%$ of the activity being lost on storage at either $4{ }^{\circ} \mathrm{C}$ or (with freezing and thawing) at $-80^{\circ} \mathrm{C}$ in $24 \mathrm{~h}$.

Acyl-CoA dehydrogenase activity was slightly higher in all extracts with decanoyl-CoA as the substrate than with palmitoyl-CoA as the substrate (Table $4 a$ ). Palmitoyl-CoA dehydrogenase activity was observed using PMS as an electron acceptor, but without $\mathrm{NAD}^{+}$, suggesting a flavin-linked enzyme of type EC 1.3.99.3 (see Methods and Fig. 2). When diaphorase and NAD ${ }^{+}$ were included in assays instead of PMS, to show NAD ${ }^{+}$linked activity, the activity was $8 \%$ of that observed with PMS ; endogenous levels of diaphorase and $\mathrm{NAD}^{+}$were negligible, as no activity was observed if either $\mathrm{NAD}^{+}$or diaphorase or both were omitted in assays without PMS. No activity was observed if $\mathrm{NADP}^{+}$was included in assays instead of PMS and DCPIP but if NADP ${ }^{+}, 0 \cdot 1$ unit ferridoxin: NADP ${ }^{+}$reductase (NADPH diaphorase) and DCPIP were included in assays instead of PMS, activity was $3 \%$ of the activity observed with PMS, indicating a trace of NADP ${ }^{+}$-linked activity. The above experiments, in which PMS was replaced with other acceptors, were done with extracts of $M$. avium and $M$. microti grown in Dubos medium and then confirmed with an extract of $M$. avium grown in mice. Activity, whether of type EC 1.3.1.8 or EC 1.3.99.3, was never detected if $p$-iodonitrotetrazolium violet was used as the terminal electron acceptor in assays in place of DCPIP. In the biosynthetic direction (see Table $4 b$ ), trans-2enoyl-CoA was reduced in the presence of NADH or NADPH, showing activity of the type EC 1.3.1.8. (see Fig. 2). This suggests that acyl-CoA dehydrogenase (EC 1.3.99.3) acts in the catabolic, $\beta$-oxidation pathway, whereas enoyl-CoA reductase acts mainly in the anabolic direction. However, the trace of $\mathrm{NAD}(\mathrm{P})^{+}$ linked acyl-linked oxidoreductase activity shown essentially the reverse reaction of enoyl-CoA reductase suggests that this enzyme activity may be able to function, perhaps as a minor activity, in the catabolic direction as well as the anabolic direction (Fig. 1).

Other key enzymes of $\beta$-oxidation in extracts of mycobacteria in vivo are shown in Table 4 . When $M$.
Table 4. Enzyme activities in extracts from host-grown mycobacteria

All assays were done at $25^{\circ} \mathrm{C}$ as indicated in Methods. Values are means of specific activities [mU (mg protein $\left.)^{-1}\right] \pm$ SEM, obtained by performing two to four (usually four) assays with each of extracts prepared from two or three isolates of host-grown bacteria, except for acetyl-CoA acyltransferase when one isolate of $M$. leprae and $M$. avium (grown in Sauton's medium) and $M$. microti (grown in Dubos medium) was used for preparing each extract.

\begin{tabular}{|c|c|c|c|}
\hline & \multicolumn{3}{|c|}{ Extract from: } \\
\hline & M. leprae & M. microti & M. avium \\
\hline \multicolumn{4}{|c|}{$\begin{array}{l}\text { (a) Assayed in the catabolic, oxidative direction } \\
\text { Acyl-CoA dehydrogenase }\end{array}$} \\
\hline $\begin{array}{l}\text { With decanoyl-CoA } \\
\text { With palmitoyl-CoA }\end{array}$ & $\begin{array}{l}2 \cdot 5 \pm 0 \cdot 1 \\
1 \cdot 5 \pm 0 \cdot 3\end{array}$ & $\begin{array}{l}16 \pm 3 \\
14 \pm 1\end{array}$ & $\begin{array}{l}31 \pm 4 \\
20 \pm 2\end{array}$ \\
\hline \multicolumn{4}{|l|}{ Enoyl-CoA hydratase } \\
\hline $\begin{array}{l}\text { With crotonyl-CoA } \\
\text { With dec-2-enoyl-CoA }\end{array}$ & $\begin{array}{l}2 \cdot 1 \pm 0 \cdot 1 \\
2 \cdot 2 \pm 0 \cdot 2\end{array}$ & $\begin{array}{l}8 \cdot 1 \pm 2 \cdot 0 \\
7 \cdot 0 \pm 0 \cdot 5\end{array}$ & $\begin{array}{l}5 \cdot 5 \pm 0.9 \\
4.9 \pm 1 \cdot 1\end{array}$ \\
\hline $\begin{array}{l}\beta \text {-Hydroxyacyl-CoA } \\
\text { dehydrogenase }\end{array}$ & \multicolumn{3}{|c|}{ Assayed in the anabolic direction only } \\
\hline \multicolumn{4}{|l|}{$\begin{array}{l}\text { Acetyl-CoA acyltransferase, } \\
\beta \text {-ketothiolase activity }\end{array}$} \\
\hline \multicolumn{4}{|c|}{$\begin{array}{l}\text { (b) Assayed in the anabolic, fatty-acyl-elongating direction } \\
\text { Enoyl-CoA reductase with } \\
\text { dec-2-enoyl-CoA* }\end{array}$} \\
\hline $\begin{array}{l}\text { With NADH } \\
\text { With NADPH }\end{array}$ & $\begin{array}{l}4 \cdot 3 \pm 1 \cdot 7 \\
4 \cdot 1 \pm 1 \cdot 9\end{array}$ & $\begin{array}{l}26 \pm 4 \\
5 \cdot 1 \pm 2 \cdot 4\end{array}$ & $\begin{array}{l}17 \pm 2 \\
10 \pm 2\end{array}$ \\
\hline Enoyl-CoA hydratase & \multicolumn{3}{|c|}{ Assayed in the catabolic direction only } \\
\hline $\begin{array}{l}\beta \text {-Hydroxyacyl-CoA } \\
\text { dehydrogenase, with } \\
\text { acetoacetyl-CoA }\end{array}$ & $170 \pm 33$ & $99 \pm 7$ & $78 \pm 11$ \\
\hline Acetyl-CoA acyltransferase & & & \\
\hline With $25 \mu \mathrm{M}$-decanoyl-CoA & ND & $0 \cdot 8 \pm 0 \cdot 3$ & $0 \cdot 6 \pm 0 \cdot 1$ \\
\hline With $25 \mu \mathrm{M}$-palmitoyl-CoA & ND & $0 \cdot 8 \pm 0 \cdot 1$ & $0 \cdot 9 \pm 0 \cdot 1$ \\
\hline With $75 \mu \mathrm{M}$-decanoyl-CoA & ND & $0 \cdot 7 \pm 0 \cdot 2$ & $0 \cdot 3 \pm 0 \cdot 1$ \\
\hline With $75 \mu \mathrm{M}$-palmitoyl-CoA & ND & $0.7 \pm 0.2$ & $0 \cdot 4 \pm 0 \cdot 1$ \\
\hline
\end{tabular}

ND, Not done.

* No activity $(<0 \cdot 2)$ detected with crotonyl-CoA.

avium was grown in Dubos medium or Dubos medium with either liposomes or triolein added, activities were similar (Table 5). However, when M. avium was grown in Dubos medium plus palmitate specific activities of all the enzymes assayed were elevated at least 4-fold (Table 5). It was important to use good quality triolein in the growth media: we used Sigma Grade, $99 \%$ pure, to obtain the above results; when we used practical grade $(65 \%$ pure) we obtained similar results to those obtained when palmitate was added to growth medium and, indeed, found that about 10 to $20 \%$ of the lipid in practical grade triolein was free fatty acid. Activities were not elevated in $M$. microti grown in Dubos medium with added palmitate, but palmitate inhibited the yield of $M$. microti by about $70 \%$ : its low growth rate may therefore result in depressed enzyme activities. 
EC 1.3.99.3

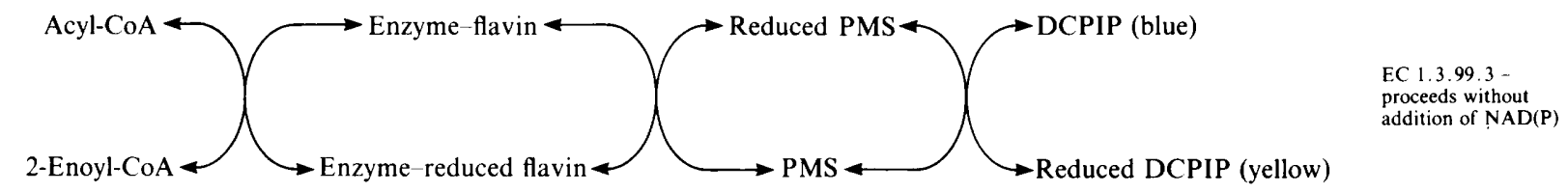

\section{EC 1.3.1.8}

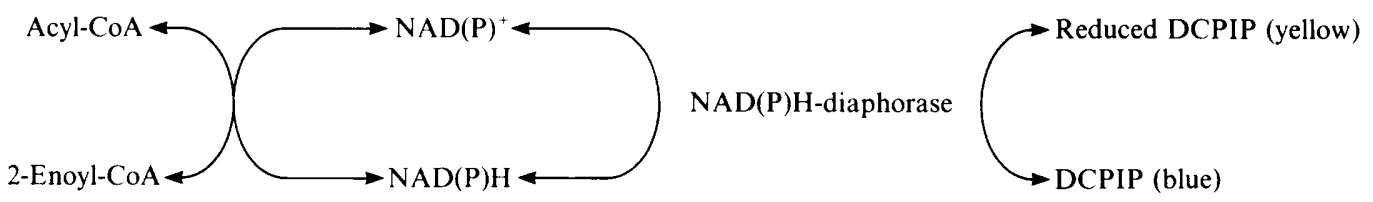

EC.1.3.1.8 - assayed with diaphorase and diaphorase and CoA reduction

Fig. 2. Assay of acyl-CoA dehydrogeanse (EC 1.3.99.3) and 2-enoyl-CoA reductase (EC 1.3.1.8) activities. Systematic enzyme names are given in Methods.

Table 5. Stimulation of enzymes for $\beta$-oxidation in $M$. avium grown in the presence of palmitate

All assays were done at $25^{\circ} \mathrm{C}$ as indicated in Methods. Values are (i) ranges of specific activities [mU (mg protein $\left.)^{-1}\right]$ for $M$. avium grown in Dubos medium with either no addition, with the addition of either triolein or liposomes (see Methods for details) or grown in mice - the activities in individual assays overlapped considerably in extracts of $M$. avium grown in these different ways, and could not be distinguished from each other; (ii) values for specific activities of $M$. avium grown in Dubos medium + palmitate (sodium salt, $100 \mu \mathrm{g}$ per $\mathrm{ml}$ of medium) are means \pm SEM, determined by performing two or three assays with each of two extracts prepared from different batches of $M$. avium.

Growth medium for $\boldsymbol{M}$. avium

Without free With sodium palmitic acid palmitate

(a) In the oxidative direction

Acyl-CoA dehydrogenase

With palmitoyl-CoA

Enoyl-CoA hydratase

With crotonyl-CoA

With 2-decenoyl-CoA

$\begin{array}{ll}16-30 & 87 \pm 10 \\ & \\ 3 \cdot 5-7 \cdot 5 & 55 \pm 13 \\ 2 \cdot 8-6 \cdot 5 & 32 \pm 6\end{array}$

(b) In the fatty acyl elongation direction

Enoyl-CoA reductase

$\begin{array}{lll}\text { With NADH } & 14-18 & 57 \pm 7\end{array}$

$\begin{array}{lll}\text { With NADPH } & 7-12 & 52 \pm 12\end{array}$

$\beta$-Hydroxyacyl-CoA dehydrogenase

$\begin{array}{lll}\text { With acetoacetyl CoA } & 55-98 & 402 \pm 64\end{array}$

Simultaneous elongation and catabolism of supplied fatty acids

When $100 \mu \mathrm{g}\left[1^{-14} \mathrm{C}\right]$ palmitate $\mathrm{ml}^{-1}$ was included in Dubos growth medium, $M$. avium [initially $6 \mathrm{mg}$ dry wt $\left(1.2 \times 10^{11}\right.$ bacteria in $\left.25 \mathrm{ml}\right]$ converted $1.4 \%(1038 \mathrm{~Bq})$ to ${ }^{14} \mathrm{CO}_{2}$. During $4 \mathrm{~h}$ growth $20 \%(14670 \mathrm{~Bq})$ of the radioactivity supplied appeared in lipids associated with the bacteria which could be extracted with chloroform/ methanol (see Methods). After methylation and fractionation by TLC, a fraction representing fatty acid methyl esters containing $4170 \mathrm{~Bq}$, could be further fractionated by $\mathrm{AgNO}_{3}$-TLC (see Methods) into saturated (86\%), monounsaturated $(12 \%)$ and diunsaturated $(2 \%)$ fatty acid methyl esters. Only $4 \mathrm{~Bq}(0 \cdot 1 \%)$ was recovered in the fraction containing esters with three or more double bonds. Radio-gas chromatography showed that $74 \%$ of the radioactivity was in esters of fatty acids of 16 or fewer carbon atoms, including 16:1 and 16:2 (which appear after 16:0 but before 18:0 in the method used). The remaining $26 \%$ of the radioactivity was associated with esters of fatty acids 18:0 or longer. Since virtually no radioactivity was detected in polyunsaturated fatty acid esters (which would be retarded during chromatography), this distribution of radioactivity shows that chain elongation was occurring. Fractionation of the longer-chain fatty acid methyl esters in a duplicate sample, in which $28 \%$ of the radioactivity was in 18:0 ester or longer chain esters, showed peaks of radioactivity associated with the following: 18:0 (8.5\% of the radioactivity in all fatty acid methyl esters $) ; 20: 0(2.0 \%)$, $21: 0$, an unidentified mycobacterial component $(2.9 \%)$; $22: 0$, a further unidentified mycobacterial component $(2.6 \%) ; 24: 0(1.4 \%)$; and a fraction including $24: 1$ and $26: 0(8 \cdot 6 \%)$.

\section{Discussion}

The results in this paper show that $M$. leprae, $M$. microti and $M$. avium catabolize exogenous fatty acids to $\mathrm{CO}_{2}$. This is done through the $\beta$-oxidation cycle for which the key enzymes have now been demonstrated (Table 4). The observation that laurate was most rapidly oxidized agrees with previous studies with other mycobacteria, 
notably host-grown $M$. lepraemurium (Camargo et al., 1979).

Uptake and utilization of decanoate and palmitate were compared in a previous paper (Wheeler et al., 1990) so, where appropriate, $\beta$-oxidation enzyme activities were assayed here using decanoyl-CoA and palmitoylCoA. The activity of acyl-CoA dehydrogenase is higher for decanoyl-CoA than for palmitoyl-CoA, as shown in extracts of all mycobacteria studied (Table $4 a$ ), which may be one of the reasons why intact mycobacteria oxidize decanoate more rapidly than palmitate (see Table 1 and the section in the Results on oxidation of fatty acids by intact mycobacteria). However, acetylCoA-dependent elongation of fatty acyl-CoA to longerchain fatty acyl-CoA esters (the complete reaction is given in Fig. 1) was previously shown to occur at a higher rate for decanoyl-CoA and palmitoyl-CoA in all mycobacteria studied (Wheeler \& Ratledge, 1990), but the first individual enzyme activity - acetyl-CoA acyltransferase - involved in elongation (Fig. 1) had similar reaction velocities for decanoyl-CoA and palmitoyl-CoA (Table $4 b$ ). Therefore, the activity of this enzyme cannot account for the greater rate of elongation of decanoylCoA by the complete elongase (Wheeler et al., 1990).

Activities of enzymes in the $\beta$-oxidation cycle did not appear to be stimulated in host-grown mycobacteria except with $M$. avium grown in the presence of a free fatty acid, in which all the individual enzyme activities were stimulated, suggesting them to be co-induced as observed in other microbes (Finnerty, 1989) including Escherichia coli (Nunn, 1986). However, $M$. avium is possibly unique and certainly different from $M$. microti in that its growth is stimulated, though slightly, by adding palmitate to the culture medium (McCarthy, 1984), whereas with $M$. microti the growth rate is diminished (Wheeler et al., 1990). (The effect of palmitate on $M$. leprae is, of course, unknown due to the inability to cultivate it axenically.)

Acetyl-CoA-dependent elongation of fatty acyl-CoA esters, which is the predominant route in mycobacteria (see also Wheeler et al., 1990), apparently involves the same enzyme activities as are found in $\beta$-oxidation enzymes but working in the opposite direction. In $E$. coli, synthesis of the enzymes is under the same regulation as catabolic $\beta$-oxidation (Nishimaki-Mogami et al., 1987). Results obtained in this study suggest that regulation of these pathways in mycobacteria is slightly different: in contrast to the activities observed for individual enzymes of $\beta$-oxidation, acetyl-CoA-dependent chain elongation is stimulated in $M$. microti and $M$. avium grown in host animals or axenically in the presence of liposomes (Wheeler et al., 1990).

$\beta$-Oxidation and chain elongation rely on the same reactions but it is inconceivable that these processes can occur simultaneously - which they do as has been shown here - and be catalysed by the same enzymes. Thus we suggest that there must be two separate enzyme complexes, functionally identical but spatially distinct. This would therefore involve the two sets of enzymes being structurally distinct as site-recognition must be different. In this way, two apparently similar enzyme complexes can simultaneously catalyse two sets of reactions but in opposite directions.

Consideration of the evidence presented in this paper suggests that there are differences between the two putative complexes. For the elongating system, the first enzyme of the sequence (see Fig. 1) is acetyl-CoA transferase. In $E$. coli, where the same processes also occur, there is no evidence for two distinct enzymes (Binstock \& Schulz 1981; Nishimaki-Mogami et al., 1987). Although Shimikata et al. (1980) reached a similar conclusion working with $M$. smegmatis, there could be more than one acetyl-CoA acyltransferase in the pathogenic mycobacteria studied here as there is clearly separate regulation of elongation and $\beta$-oxidation. Such regulation could be argued to occur at this first reaction as the equilibrium strongly favours the reverse (cleavage) reaction. Thus to achieve elongation, the condensation reaction must be highly integrated as part of a complex to ensure that the product of the reaction ( $\beta$-ketoacyl-CoA) is rapidly removed.

For $\beta$-oxidation, the first individual enzyme that acylCoA must bind to is acyl-CoA dehydrogenase (Fig. 1). In $E$. coli, this enzyme is different from that involved in acetyl-CoA-dependent chain elongation, which is a specific trans-2-enoyl-CoA reductase (Mizugaki et al., 1982). Likewise, the flavin-linked acyl-CoA dehydrogenase, demonstrated in this work, is possibly involved in catabolism of fatty acids while the NADP $(\mathrm{H})$-dependent enoyl-CoA oxidoreductase is part of the elongating complex.

Enoyl-CoA hydratase is another activity for which there could be separate enzymes involved in acetyl-CoAdependent chain elongation and oxidation. In $E$. coli, polyclonal antibodies raised against the $\beta$-oxidation complex also inhibited acetyl-CoA-dependent chain elongation, providing further evidence for the involvement of similar enzymes in $\beta$-oxidation and elongation; however, the antibodies did not completely inhibit hydratase activity with dec-2-enoyl-CoA. For $M$. smegmatis, two distinct enoyl-CoA hydratases have been purified (Fujita et al., 1980). One (type I) had activity for crotonoyl-CoA and dec-2-enoyl-CoA; the other (type II), which was the only one that participated in acetyl-CoAdependent acyl-CoA elongation, had no activity with crotonyl-CoA but was active with dec-2-enoyl-CoA. In the present study using crude extracts, activity with both crotonyl-CoA and dec-2-enoyl-CoA was observed. As 
the purified type I enzyme from $M$. smegmatis has about ten times greater activity with crotonyl-CoA than with dec-2-enoyl-CoA (Fujita et al., 1980), the results in Table 4(a) suggest that type II hydratase must have been present along with type I hydratase.

Overall, the present work shows that all the enzyme activities for $\beta$-oxidation and acetyl-CoA-dependent chain elongation exist in pathogenic mycobacteria. Further progress will require the purification of enzymes so that similar enzymes can be distinguished and the stereospecificity of the substrates worked out.

Finally, as antileprosy agents inhibited the evolution of ${ }^{14} \mathrm{CO}_{2}$ from $\left[1-{ }^{14} \mathrm{C}\right]$ laurate and the rate of evolution of ${ }^{14} \mathrm{CO}_{2}$ from this substrate was considerably higher than with $\left[1-{ }^{14} \mathrm{C}\right]$ palmitate, the former substrate should replace $\left[1-{ }^{14} \mathrm{C}\right]$ palmitate in the potential drug-screening methods developed by Franzblau (1988), which depend on oxidation of ${ }^{14} \mathrm{C}$-labelled fatty acids to ${ }^{14} \mathrm{CO}_{2}$. This would give a 3- to 4-fold increase in the sensitivity of such a test system.

P.R.W. is grateful to the UNDP/World Bank/WHO Special Programme for Research and Training in Tropical Diseases for financial support during the course of this investigation. LEPRA and the WHO (IMMLEP programme) provided funds for the maintenance of armadillo colonies.

\section{References}

BARCLAY, R. \& WHEELER, P. R. (1989). Metabolism of mycobacteria in tissues. In The Biology of the Mycobacteria, vol. 3, pp. 37-106. Edited by C. Ratledge, J. Stanford \& J. M. Grange. London: Academic Press.

Binstock, J. R. \& Schulz, H. (1981). Fatty acid oxidation complex from Escherichia coli. Methods in Enzymology 71, 403-411.

Camargo, E. E. \& W AGner, H. N., JR (1987). Radiometric studies on the oxidation of $\left[1-1^{14} \mathrm{C}\right]$ fatty acids and $\left[\mathrm{U}-{ }^{14} \mathrm{C}\right] \mathrm{L}$-amino acids by mycobacteria. Nuclear Medicine and Biology 14, 43-49.

Camargo, E. E., Kertcher, J. A., Larson, S. M., Tepper, B. S. \& W AGNER, H. N., JR. (1979). Radiometric measurement of differential metabolism of fatty acids by Mycobacterium lepraemurium. International Journal of Leprosy 47, 126-132.

CHADwick, M. V. (1982). Mycobacteria. Institute for Medical Laboratory Sciences Monographs. Bristol: P. S. G. Wright.

Colquhoun, D. (1971). Numerical and rank measurements. In Lectures on Biostatistics, pp. 137-151. Oxford: Clarendon Press.

Finnerty, W. R. (1989). Microbial lipid metabolism. In Microbial Lipids, vol. 2, pp. 525-566. Edited by C. Ratledge \& S. G. Wilkinson. London: Academic Press.

FranzblaU, S. G. (1988). Oxidation of palmitic acid by Mycobacterium leprae in an axenic medium. Journal of Clinical Microbiology 26, 1821.

Franzblau, S. G., Harris, E. B. \& Hastings, R. C. (1987). Axenic incorporation of [U-14 C]palmitic acid into the phenolic glycolipid-I of Mycobacterium leprae. FEMS Microbiology Letters 48, 407-411.

Fujita, Y., Shimikata, T. \& Kusaka, T. (1980). Purification of two forms of enoyl-CoA hydratase from Mycobacterium smegmatis. Journal of Biochemistry 88, 1045-1050.
Heifets, L. B., Iseman, M. D., CoOK, J. L., Lindholm-Levy, P. J. \& DRUPA, I. (1985). Determination of in vitro susceptibility of Mycobacterium tuberculosis to cephalosporins by radiometric and conventional methods. Antimicrobial Agents and Chemotherapy 27, $11-15$.

ISHAQUE, M. (1989). Direct evidence for the oxidation of palmitic acid by host grown Mycobacterium leprae. Research in Microbiology 140, 83-93.

KIKUCHI, S. \& KuSaKa, T. (1984). Purification of NADPH-dependent enoyl-CoA reductase involved in the malonyl-CoA dependent fatty acid elongation system of Mycobacterium smegmatis. Journal of Biochemistry 96, 841-848.

Kondo, E., Suzuki, K., KanaI, K. \& Yasuda, T. (1985). Liposomesmycobacteria incubation systems as a partial model of host-parasite interaction at cell membrane level. Japanese Journal of Medical Science and Biology 38, 169-180.

KUSAKA, T. (1977). Fatty acid synthesizing enzyme activity of cultured Mycobacterium lepraemurium. International Journal of Leprosy 45, 132-144.

LOWRIE, D. B. (1983). Mononuclear phagocyte-mycobacterium interaction. In The Biology of the Mycobacteria, vol. 2, pp. 235-278. Edited by C. Ratledge \& J. Stanford. London: Academic Press.

MCCARTHY, C. (1984). Free fatty acid and triglyceride content of Mycobacterium avium cultured under different growth conditions. American Review of Respiratory Disease 129, 96-100.

Minnikin, D. E., Hutchinson, I. G. \& Caldicott, A. B. (1980). Chromatography of methanolysates of mycolic acid containing mycobacteria. Journal of Chromatography 188, 221-233.

MizugaKi, M., Nishimaki, T., Shiraishi, T. \& YamanaKa, H. (1982). Studies on metabolism of unsaturated fatty acids. VII. Separation and general properties of reduced nicotinamide adenine dinucleotide phosphate-dependent trans-2-enoyl-coenzyme-CoA reductase from Escherichia coli K-12. Chemical Pharmacology Bulletin 30, 2503-2511.

MukHERJEe, R. M. \& ANTIA, N. H. (1985). Intracellular multiplication of leprosy-derived mycobacteria in Schwann cells of dorsal root ganglian cultures. Journal of Clinical Microbiology 21, 208-212.

Nishimaki-Mogami, T., Yamanaka, H. \& Mizugaki, M. (1987). Involvement of the fatty acid oxidation complex in acetyl-CoAdependent chain elongation of fatty acids in Escherichia coli. Journal of Biochemistry 102, 427-432.

NunN, W. D. (1986). A molecular view of fatty acid catabolism in Escherichia coli. Microbiological Reviews 50, 179-192.

Schulz, R. (1974). Long chain enoyl-CoA hydratase from pig heart. Journal of Biological Chemistry 249, 2704-2709.

Shimikata, T., FujITA, Y. \& KUSAKA, T. (1980). Involvement of one or two enoyl-CoA hydratase and enoyl-CoA reductase in the acetylCoA-dependent elongation of medium chain fatty acids by $M y c o b a c$ terium smegmatis. Journal of Biochemistry 88, 1051-1058.

WhEELER, P. R. (1984). Oxidation of carbon sources through the tricarboxylic acid cycle in Mycobacterium leprae grown in armadillo liver. Journal of General Microbiology 130, 381-389.

WhEELER, P. R. (1987). Biosynthesis and scavenging of purines by pathogenic mycobacteria including Mycobacterium leprae. Journal of General Microbiology 133, 2999-3011.

WheELER, P. R. \& RATLEDGE, C. (1988). Use of carbon sources for lipid biosynthesis in Mycobacterium leprae: a comparison with other pathogenic mycobacteria. Journal of General Microbiology 134, 2111 2121 .

Wheeler, P. R., BharadwaJ, V. P. \& Gregory, D. (1982). N-Acetyl$\beta$-glucosaminidase, $\beta$-glucuronidase and acid phosphatase in $\mathrm{Myco}$ bacterium leprae. Journal of General Microbiology 128, 1063-1071.

WheEler, P. R., Bulmer, K. \& Ratledge, C. (1990). Enzymes for biosynthesis de novo and elongation of fatty acids in mycobacteria: is Mycobacterium leprae competent in fatty acid biosynthesis? Journal of General Microbiology 136, 211-217.

WORLD Health ORganization (1980). UNDP/World Bank/WHO Special Programme for Research and Training in Tropical Diseases. Report of the fifth Meeting on the Immunology of Leprosy (IMMLEP). TDR/IMMLEP-SWG (5)/80.3, Annex 4, p. 23. Geneva: World Health Organization. 